ARTIGOS

\title{
AUSTERIDADE FISCAL E O FINANCIAMENTO DA EDUCAÇÃO NO BRASIL
}

\author{
Pedro Rossi ${ }^{1}$ (D) \\ Ana Luíza Matos de Oliveira ${ }^{2}$ (D \\ Flávio Arantes ${ }^{1}$ (D) \\ Esther DweCK ${ }^{3}$ (1)
}

\begin{abstract}
RESUMO: O objetivo deste artigo é analisar as repercussóes da austeridade fiscal no Brasil, em especial no campo do financiamento da educação. Para isso, faz-se inicialmente uma discussão conceitual sobre a austeridade, a sua lógica de funcionamento, seus mitos e os interesses velados por trás dessa concepção de política econômica. Em seguida, mostra-se como a austeridade no Brasil é um projeto de longo prazo instituído pela Emenda Constitucional 95 que repercutirá no financiamento da educação pública tanto pela nova regra do mínimo constitucional quanto pela disputa de recursos com outras áreas sociais. E, por fim, apresentam-se os dados orçamentários recentes que mostram os impactos que a austeridade já tem provocado no campo da educação pública.
\end{abstract}

Palavras-chave: Austeridade fiscal. Educação pública. Emenda Constitucional 95.

\section{FISCAL AUSTERITY AND THE FINANCING OF EDUCATION IN BRAZIL}

ABSTRACT: This paper aims to analyze the repercussions of fiscal austerity in Brazil, especially in the field of education financing. For this, a conceptual discussion on austerity is undertaken, its working logic, its myths and hidden interests behind this conception of economic policy is initially made. It then shows how austerity in Brazil is a longterm project instituted by Constitutional Amendment 95 that will affect the financing of public education both by the new constitutional

\footnotetext{
${ }^{1}$ Universidade Estadual de Campinas - Campinas (SP), Brasil. E-mails: pedrolrossi@gmail.com; flarantes@gmail.com

${ }^{2}$ Faculdade Latino-Americana de Ciências Sociais - Rio de Janeiro (RJ), Brasil.

E-mail: almatosdeoliveira@gmail.com

${ }^{3}$ Universidade Federal do Rio de Janeiro - Rio de Janeiro (RJ), Brasil. E-mail: esther.dweck@gmail.com DOI: 10.1590/ES0101-73302019223456
} 
minimum rule and by the dispute of resources with other social areas. Finally, we present the recent budgetary data which shows the impacts that austerity has already provoked in the field of public education.

Keywords: Fiscal austerity. Public education. Constitutional Amendment 95.

\section{AUSTERIDAD FISCAL Y FINANCIAMIENTO DE LA EDUCACIÓN EN BRASIL}

RESUMEN: El propósito de este artículo es analizar las repercusiones de la austeridad fiscal en Brasil, especialmente en el campo de la financiación de la educación. Para esto, inicialmente se realiza una discusión conceptual sobre la austeridad, su lógica de operación, sus mitos y los intereses velados detrás de esta concepción de la política económica. A continuación se muestra cómo la austeridad en Brasil es un proyecto a largo plazo instituido por la Enmienda Constitucional 95 que impactará el financiamiento de la educación pública tanto por la nueva norma mínima constitucional como por la disputa sobre recursos con otras áreas sociales. Finalmente, son presentados los datos presupuestarios recientes que muestran los impactos que la austeridad ya ha tenido en la educación pública.

Palabras clave: Austeridad fiscal. Educación pública. Enmienda Constitucional 95.

\section{Introdução}

A

austeridade pode ser definida como uma política de ajuste da economia fundada na redução dos gastos públicos e do papel do Estado em suas funções de indutor do crescimento econômico e promotor do bem-estar social. As práticas políticas em nome dessa ideia assumiram protagonismo no Brasil em 2015 como um plano de ajuste de curto prazo da economia brasileira. Porém, em 2016, os princípios da austeridade passaram a nortear o setor público de forma estrutural com a Emenda Constitucional 95 (EC95) que impóe uma reduçáo do tamanho relativo do Estado para os próximos 20 anos.

Essa nova forma de gestão do orçamento público tem consequências macroeconômicas e distributivas e condiciona a capacidade dos governos de induzir o crescimento econômico e de promover o bem-estar social, conforme discutido na literatura econômica ${ }^{1}$. Tal mudança também afeta o financiamento da atuação pública em diversos campos sociais como na educação. 
Nesse contexto, este artigo discute a austeridade fiscal e os seus efeitos já observados e esperados - no financiamento da educação pública brasileira. Para isso, divide-se em três seçóes para além desta introdução e das consideraçóes finais. Na primeira, discutem-se o conceito e a lógica subjacente à defesa da austeridade destacando os elementos políticos e ideológicos por trás desse discurso e descrevem-se os mitos que sustentam o discurso da austeridade como o da fada da confiança e a metáfora do orçamento doméstico e apontam-se os interesses velados.

Já a segunda seção do artigo analisa, no caso brasileiro, como a ideia de austeridade, mais do que uma política de ajuste temporária, é um projeto de longo prazo instituído pela EC95. Além disso, por meio de simulaçóes, a parte seguinte deste trabalho aponta os impactos esperados no financiamento da educaçáo. Por fim, a última seção analisa os efeitos que a austeridade fiscal já vem provocando no orçamento público federal para a área de educação.

\section{Economia política da austeridade}

\section{Sobre o conceito de austeridade}

O tema da austeridade ganhou destaque após a crise internacional de 2008. Na Inglaterra, enquanto o líder conservador David Cameron proclamou que o país entrava na Era da Austeridade, o debate econômico dividiu-se entre defensores e críticos da medida. Em 2010, o dicionário Merriam-Webster's, um dos mais importantes da língua inglesa, elegeu a palavra austeridade como a palavra do ano com base no número de pesquisas feitas na internet. Com o aprofundamento da crise na Europa, e a imposição de planos de austeridade a países da periferia, cresceram os movimentos antiausteridade, assim como o debate acadêmico em torno do tema. Para além de inúmeros artigos acadêmicos, diversos livros abordaram o tema com ênfases variadas como, por exemplo, na história intelectual e política do termo (BLYTH, 2013; SCHUI, 2014), sobre seus impactos sociais (RAO, 2015) e na saúde das pessoas (STUCKLER; BASU, 2014; KELLY; PYKE, 2017; MENDOZA, 2015), assim como nos fundamentos econômicos, como em Atkinson (2014) e Skidelsky Fraccaroli (2017) e também literatura voltada para análise dos movimentos sociais antiausteridade, como em Cammaerts (2018).

Austeridade não é um termo de origem econômica. A palavra tem origens na filosofia moral e aparece no vocabulário econômico como um neologismo que se apropria da carga moral do termo, especialmente para exaltar o comportamento associado ao rigor, à disciplina, aos sacrifícios, à parcimônia, à prudência, à sobriedade e reprimir comportamentos dispendiosos, insaciáveis, pródigos, perdulários. Para Coelho (2014), o discurso da austeridade no campo econômico tem profunda raiz cultural e traços religiosos, pois prega a redenção ou recompensa por sacrifícios prestados. Como veremos mais adiante, o discurso moderno da 
austeridade ainda carrega essa carga moral e transpóe, sem adequadas mediaçóes, essas supostas virtudes do indivíduo para o plano público, personificando, atribuindo características humanas ao governo.

Como aponta Schui (2014), os argumentos em defesa da austeridade econômica vêm de longa data e remetem a pensadores pré-modernos como Aquino e Aristóteles. Tais argumentos estão associados à discussão sobre o modo de vida e o manejo dos recursos do indivíduo e das famílias para uma vida boa. $\mathrm{O}$ termo austeridade também ganha proeminência nas grandes guerras mundiais, quando é apropriado por um discurso do governo que busca legitimar o racionamento e a regulaçáo do consumo privado em prol da mobilização dos recursos da sociedade para o esforço de guerra. No imediato pós-guerra, a austeridade continua em voga por conta da necessidade de priorizar a reconstrução de países que foram destruídos, as exportaçóes, os investimentos, e o provimento de bens públicos em detrimento do consumo privado (ZWEINIGER-BARGIELOWSKA, 2000). Nesse contexto, o discurso da austeridade não estava ligado à redução do gasto público, mas, pelo contrário, tratava-se de conter o consumo privado para que o governo pudesse atuar fortemente na alocação de recursos. Curiosamente, na Inglaterra do pós-guerra, era um governo de esquerda, do trabalhista Clement Attlee, que defendia a austeridade, ou seja, a manutenção dos controles da economia de guerra e a contençáo do consumo privado para direcioná-los para o provimento de bens públicos de consumo coletivo, como saúde, educação, moradia etc. (ZWEINIGER-BARGIELOWSKA, 2000).

Segundo Blyth (2013), o argumento moderno pela austeridade foi desenvolvido por um grupo de acadêmicos do qual o mais proeminente é Alberto Alesina ${ }^{2}$. A intuição básica do argumento é que, em tempos de crise, as políticas fiscais restritivas (aumento de impostos ou, preferencialmente, redução de gastos) podem ter efeito expansionista, de aumento do crescimento econômico. O debate econômico em torno dos efeitos da contraçáo fiscal deu corpo ao conceito de austeridade que pode ser definido por seu instrumento (ajuste fiscal - de preferência corte de gastos) e seus objetivos (gerar crescimento econômico/equilibrar as contas públicas). Nesse sentido, a austeridade é a política que busca, por meio de um ajuste fiscal, cortar gastos, ajustar a economia e promover o crescimento, preferivelmente. Seus resultados e sua racionale são explorados na próxima subseção.

\section{A lógica da austeridade}

A defesa da austeridade fiscal sustenta que, diante de uma desaceleração econômica e de um aumento da dívida pública, o governo deve realizar um ajuste fiscal, preferencialmente com corte de gastos públicos em detrimento de aumento de impostos. Esse ajuste teria efeitos positivos sobre o crescimento econômico ao melhorar a confiança dos agentes na economia. Ou seja, ao mostrar 
responsabilidade em relação às contas públicas, o governo ganha credibilidade com os agentes econômicos e, diante da melhora nas expectativas, a economia passa por uma recuperaçáo decorrente do aumento do investimento dos empresários, do consumo das famílias e da atração de capitais externos. A austeridade teria, portanto, a capacidade de reequilibrar a economia, reduzir a dívida pública e retomar o crescimento econômico.

No plano da teoria econômica, esse efeito decorre do pressuposto de que o setor público e o setor privado disputam recursos, ou poupança, e que uma redução do gasto público abre espaço para o investimento privado. Como argumenta o economista de Chicago John Cochrane (2009), a cada dólar adicional gasto pelo governo é um dólar a menos gasto pelo setor privado, o impulso fiscal pode criar rodovias em vez de fábricas, mas não pode criar os dois. A austeridade expansionista dá um passo adicional nesse argumento ao propor que, dada a maior eficiência do gasto privado, a contração do gasto público gera um aumento ainda maior do gasto privado ${ }^{3}$.

Esses pressupostos são contrários ao que propõe John M. Keynes (1937) para quem essa disputa por recurso entre o setor privado e o setor público depende do ciclo econômico. Para Keynes (1937), é no boom e não na crise que o governo pode cortar gastos, nos casos de excesso de demanda na economia. E o raciocínio do autor é bastante intuitivo: na crise, como os recursos da sociedade estão subempregados, o aumento do gasto público gera crescimento e emprego, enquanto que nos momentos de boom, os gastos públicos teriam efeito menor sobre a atividade econômica, dado que o setor privado estaria atuando de forma expansionista. Ou seja, quando a economia está aquecida, o corte do investimento em uma obra pública, por exemplo, pode não ter um efeito táo negativo na economia, uma vez que a empresa que seria contratada pelo governo poderá ser contratada por outra pessoa ou empresa privada. Da mesma forma, a redução das transferências sociais pode ter impactos distributivos negativos, mas não necessariamente contracionistas. Já o mesmo não ocorre quando há escassez de demanda, desemprego e excesso de capacidade ociosa na economia. Nesse caso, a demanda pública aumenta renda e emprego.

Assim, os efeitos da austeridade podem ser entendidos de forma intuitiva. Gasto e renda são dois lados da mesma moeda, o gasto de alguém é a renda de outra pessoa: quando alguém gasta, alguém recebe. Quando o governo contrai o seu gasto, milhóes de pessoas passam a receber menos, o que gera impactos negativos na renda privada. Quando o governo corta gastos em investimentos destinados a uma obra pública, por exemplo, o efeito é direto sobre a renda e o emprego, uma vez que a empresa que seria contratada deixa de dar emprego e comprar materiais. Da mesma forma, o corte de gastos em transferências sociais reduz a demanda dos que recebem os benefícios e desacelera o circuito da renda. Dessa forma, é uma falácia pensar o governo independente do resto da economia. Contabilmente, o gasto público é receita do setor privado, assim como a dívida 
pública é ativo privado e o déficit público é superávit do setor privado. Se no momento de crise o governo buscar superávits, estes se darão às custas dos déficits do setor privado, o que pode náo ser saudável para a estabilidade econômica e resultar no chamado ajuste fiscal autodestrutivo.

Além de gerar retração econômica, a austeridade ainda pode piorar a situação fiscal. Em uma economia em crise, a austeridade pode gerar um círculo vicioso em que o corte de gastos reduz o crescimento, o que deteriora a arrecadaçáo e piora o resultado fiscal, levando a novos cortes de gastos. Ou seja, em um contexto de crise econômica, a austeridade é contraproducente e tende a provocar queda no crescimento e aumento da dívida pública, resultado contrário ao que se propóe.

\section{Mitos do discurso da austeridade}

O discurso da austeridade é acompanhado de duas ideias extremamente questionáveis conhecidas pelos críticos como a fada da confiança e a metáfora do orçamento doméstico.

\section{Fada da confiança}

O pressuposto teórico para o sucesso das políticas de austeridade é o aumento da confiança dos agentes privados. A austeridade é o instrumento e a solução para restaurar a confiança do mercado o que, por sua vez, seria causadora de crescimento econômico. $\mathrm{Na}$ retórica austera, a busca pela confiança do mercado é muito presente, tanto no exterior como no Brasil. São inúmeros os exemplos em que a equipe econômica evoca esse tema como justificativa para cortes de gastos como em 2016, quando Henrique Meirelles estabelece que o "desafio número 1" é a retomada da confiança (REDAÇÃO, 2016) ou em 2015, quando Joaquim Levy declara que "alcançar essa meta será fundamental para o aumento da confiança na economia brasileira" (apud MARTELLO; MATOSO; CALGARO, 2014). Ou, ainda, em 2018, quando Michel Temer cita "confiança" como palavra-chave que permite a retomada do crescimento econômico no país (AQUINO, 2018).

Para Krugman (2015), a crença de que a austeridade gera confiança é baseada em uma fantasia na qual se acredita que, por um lado, os governos são reféns de vigilantes invisíveis da dívida que punem pelo mau comportamento e, por outro lado, existe uma fada da confiança que recompensará o bom comportamento. $\mathrm{O}$ autor ainda mostra evidências de que os países europeus que mais aplicaram a austeridade foram os que menos cresceram (KRUGMAN, 2015). Na mesma linha, Skidelsky e Fraccaroli (2017) mostram que a confiança não é causa, mas acompanha o desempenho econômico e que austeridade náo aumenta, mas diminui a confiança ao gerar recessão. 
Nesse sentido, também é intuitivo pensar por que um ajuste fiscal não necessariamente melhora a confiança. Um empresário não investe porque o governo faz ajuste fiscal, e sim quando há demanda por seus produtos e perspectivas de lucro. Nesse ponto, a contração do gasto público em momentos de crise não aumenta a demanda, ao contrário, essa contração reduz a demanda no sistema. Em uma grave crise econômica, quando todos os elementos da demanda privada (o consumo das famílias, o investimento e a demanda externa) estão desacelerando, se o governo contrair a demanda pública, a crise se agrava.

\section{Metáfora do orçamento doméstico}

$\mathrm{Na}$ retórica da austeridade é muito comum a comparação do orçamento público com o orçamento doméstico. Assim como uma família, o governo não deve gastar mais do que ganha. Logo, diante de uma crise e de um aumento das dívidas, deve-se passar por sacrifícios e por um esforço de poupança. No caso brasileiro, é comum a análise de que os excessos (de gastos sociais, de aumento de salário mínimo, de intervencionismo estatal etc.) estão cobrando os sacrifícios necessários ${ }^{4}$. Como na fábula da cigarra e da formiga, os excessos serão punidos e os sacrifícios, recompensados. Dessa forma, há um argumento moral de que os anos de excessos devem ser remediados com abstinência e sacrifícios e a austeridade é o remédio.

No entanto, essa comparação entre o orçamento público e o familiar não é apenas parcial e simplificadora, mas essencialmente equivocada ${ }^{5}$. Isso porque desconsidera três fatores fundamentais. O primeiro é que o governo, diferentemente das famílias, tem a capacidade de definir o seu orçamento. A arrecadação de impostos decorre de uma decisão política e está ao alcance do governo, por exemplo, tributar pessoas ricas ou importaçóes de bens de luxo, para não fechar hospitais. Ou seja, enquanto uma família não pode definir o quanto ganha, o orçamento público decorre de uma decisão coletiva sobre quem paga e quem recebe, quanto paga e quanto recebe.

O segundo fator que diferencia o governo das famílias é que, quando o governo gasta, parte dessa renda retorna sob a forma de impostos. Ou seja, ao acelerar o crescimento econômico com políticas de estímulo, o governo está aumentando também a sua receita. Como visto, o gasto público em momentos de crise econômica, principalmente com alto desemprego e alta capacidade produtiva ociosa, incentiva/promove a ocupação da capacidade, reduz o desemprego e gera crescimento. Por fim, o terceiro fator não é menos importante: as famílias não emitem moeda, não têm capacidade de emitir títulos em sua própria moeda nem definem a taxa de juros das dívidas que pagam. Já o governo faz tudo isso.

Portanto, a metáfora que compara os orçamentos público e familiar é dissimulada e desvirtua as responsabilidades que a política fiscal tem na economia, 
em suas tarefas de induzir o crescimento e amortecer os impactos dos ciclos econômicos na vida das pessoas. A administração do orçamento do governo não somente não deve seguir a lógica do orçamento doméstico, mas deve seguir a lógica oposta. Quando as famílias e empresas contraem o gasto, o governo deve ampliar o gasto de forma a contrapor o efeito contracionista do setor privado.

\section{Quem ganha com a austeridade?}

Segundo Krugman (2015), quase ninguém acredita no discurso que dominou o debate econômico europeu por volta de 2010. A austeridade é um culto em decadência e a pesquisa que dava suporte para ela foi desacreditada. Como defendido em artigo coletivo publicado no jornal The Guardian, a austeridade não tem amparo na teoria econômica e a oposição à austeridade é mainstream (BLANCHFLOWER et al., 2015). Mesmo instituiçóes conservadoras como o Fundo Monetário Internacional (FMI) reconhecem o estrago que os cortes de gasto podem fazer em uma economia frágil. A austeridade é, portanto, uma ideia equivocada do ponto de vista social e contraproducente do ponto de vista do crescimento econômico e do equilíbrio fiscal.

No entanto, como defende Milios (2015), a austeridade não é irracional, tampouco estritamente errada. Ela nada mais é do que a imposição dos interesses de classe dos capitalistas. Trata-se de uma política de classe ou uma resposta dos governos às demandas do mercado e das elites econômicas à custa de direitos sociais da população e dos acordos democráticos. Os capitalistas, por sua vez, se beneficiam das políticas de austeridade em três frentes:

- ao gerar recessão e desemprego, reduzem-se pressóes salariais e aumenta-se lucratividade. E como mostram Bova, Kinda e Woo (2018), a austeridade tende a aumentar a desigualdade de renda: em média, um ajuste de $1 \%$ do PIB está associado a aumento no coeficiente de Gini do rendimento disponível de cerca de 0,4 a $0,7 \%$ nos dois anos seguintes ${ }^{6}$;

- o corte de gastos e a redução das obrigaçóes sociais abrem espaço para futuros cortes de impostos das empresas e das elites econômicas;

- a redução da quantidade e da qualidade dos serviços públicos aumenta a demanda de parte da populaçáo por serviços privados em setores como educação e saúde, o que aumenta os espaços de acumulação de lucro privado.

A austeridade é, também, um dos três pilares centrais do neoliberalismo, juntamente com a liberalização dos mercados e as privatizaçóes (ANSTEAD, 2017). A racionalidade dessa política é, portanto, a defesa de interesses específicos 
e é ainda um veículo para corroer a democracia e fortalecer o poder corporativo no sistema político?.

Essa perspectiva traz luz para a realidade brasileira, na qual as medidas de austeridade acontecem em um período de extrema instabilidade política e de aumento das tensôes de classes. Nesse contexto, a austeridade opóe as vítimas dos cortes (principalmente a parcela mais pobre da população) aos perpetradores dessas políticas (o sistema financeiro, as elites econômicas e um governo subserviente). No Brasil, a austeridade realiza a ambição de segmentos políticos conservadores, que é almejada há décadas: revogar o contrato social da Constituição Federal de 1988 (CF/88) e aprofundar as reformas neoliberais.

\section{Austeridade fiscal no Brasil: um projeto a longo prazo}

Ao longo da década de 1980, o Brasil presenciou uma efervescência política com grandes mobilizaçôes populares, greves, conflitos e extensos debates públicos que culminaram em um grande acordo político, a $\mathrm{CF} / 88$. A chamada Constituição Cidadá sela um pacto social no Brasil que oferece ampla garantia dos direitos individuais e coletivos e o mais completo conjunto de direitos sociais que o país conheceu, além de vasta cobertura da seguridade social, que se tornou um dos maiores programas de proteção social de todo o mundo. Esses direitos sociais demandam gastos públicos para a sua efetivação que, por sua vez, exigem mecanismos de financiamento tributários.

Desde a Constituição Federal (CF) de 1934, o principal mecanismo de financiamento da educação é a vinculação de um percentual mínimo de recursos tributários, conforme apontam Pinto e Adriāo (2006). Esse mecanismo de financiamento foi interrompido em períodos ditatoriais: o primeiro marcado pela $\mathrm{CF}$ de 1937, e o segundo na CF de 1967, originária do golpe militar de 1964, que suprimiu a vinculação constitucional de recursos para a educação, diminuindo os investimentos governamentais nessa área em relação a outros gastos. Com a redemocratização, a sociedade escolheu reverter o descaso com o gasto em educação e definiu a área como prioridade. Com isso, o texto constitucional de 1988, em seu Artigo 212, ampliou o mínimo para os gastos públicos da União com educação para 18\% da Receita Líquida de Impostos (RLI) e manteve a vinculação de 25\% de receitas para os estados e municípios ${ }^{8}$. Essa vinculação, que garantiu o crescimento das receitas para a área de educaçáa, é desfeita pela EC95 de 2016.

A EC95 estabelece um novo regime fiscal, instituindo uma regra para as despesas primárias do Governo Federal com duração para 20 anos e possibilidade de revisão - restrita ao índice de correção - em 10 anos. Nessa regra, o gasto primário do governo federal fica limitado por um teto definido pelo montante gasto no ano de 2017 reajustados pela inflação acumulada, medida pelo Índice 
Nacional de Preços ao Consumidor Amplo (IPCA). Em síntese, o novo regime fiscal implica congelamento real das despesas do Governo Federal, o que resulta em redução do gasto público em relação ao PIB e ao número de habitantes, por causa do crescimento da economia e da populaçáo ao longo dos anos. Ou seja, de acordo com a regra proposta, os gastos públicos náo vão acompanhar o crescimento da renda e da população.

O Gráfico 1 apresenta o gasto primário do Governo Central do PIB, em porcentagem, desde 1997 e uma projeçâo a partir de 2017 até 2037. Em 20 anos, no período de 1997 a 2017, o gasto primário do governo central cresceu de 14 para $19 \%$ do PIB $^{9}$. Esse crescimento reflete a regulamentaçâo dos direitos sociais conforme foi pactuado na CF/88. Já nos próximos 20 anos, de 2017 a 2037, estima-se que o gasto primário do Governo Federal retorne para a casa de 14\% do PIB. As projeções levam em consideração as despesas primárias do Governo Central (União, INSS e Banco Central) segundo os dados do Tesouro Nacional. Para o ano de 2019, usamos a projeção de crescimento real do PIB de $1 \%$. A partir de 2020, pressupomos crescimento real de $2 \%$ para o PIB, mantendo as despesas primárias sem crescimento real conforme a EC9510.

Nesse contexto, a EC95 propóe retroceder nos próximos 20 anos o que o país avançou nos últimos 20 anos em termos de gastos públicos, fundamentais para a consolidação dos direitos sociais no Brasil. Essa drástica redução da participação do Estado na economia é representativa de outro projeto de país, diferente daquele almejado pela Constituiçáo de 1988, uma vez que reduz substancialmente os recursos públicos para garantia de direitos sociais como saúde, educação, previdência e assistência social.

\section{Gráfico 1}

Gasto primário do Governo Federal em porcentagem do produto interno bruto (PIB), antes da Emenda Constitucional no 95 (EC 95) e projeção até 2037.

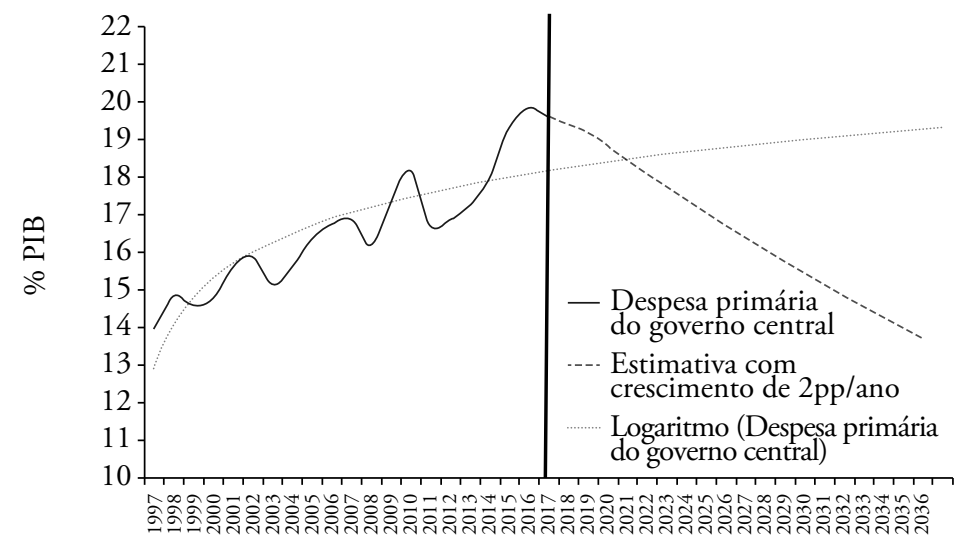

Fonte: com base em dados do Tesouro Nacional. 
Além disso, o estabelecimento de uma regra para gasto público, tal como a brasileira, é inédito em termos internacionais e não há nenhum país do mundo que estabeleceu uma regra para gasto público de crescimento real nulo, por meio de uma emenda na Constituição ${ }^{11}$. Segundo Rossi e Dweck (2016), a regra fiscal de teto para gastos primários náo exigia nenhuma mudança constitucional. A única matéria constitucional da EC95 foi a desvinculação das receitas destinadas à saúde e à educação. Ou seja, se não fosse o objetivo de desvincular esses gastos da arrecadação, não teria sido necessário que a mudança fiscal tramitasse como emenda constitucional. Nesse ponto, a EC95 estabelece um novo mínimo para os gastos da União com saúde e educação.

$\mathrm{Na}$ vigência do Novo Regime Fiscal, as aplicações mínimas em açóes e serviços públicos de saúde e em manutenção e desenvolvimento do ensino equivalerão: I - no exercício de 2017, às aplicaçóes mínimas calculadas nos termos do inciso I do $\$ 2^{\circ}$ do art. 198 e do caput do art. 212, da Constituição Federal; e II - nos exercícios posteriores, aos valores calculados para as aplicaçóes mínimas do exercício imediatamente anterior, corrigidos na forma estabelecida pelo inciso II do $\$ 1^{\circ}$ do art. 107 deste Ato das Disposiçóes Constitucionais Transitórias (BRASIL, 2016).

Para o caso da educação, a EC95 institui que o gasto mínimo da União para os próximos 20 anos será $18 \%$ da receita líquidas de impostos de 2017 reajustado pela inflaçáo. Ou seja, o piso do gasto federal real com educação será congelado no patamar de 2017. Ao comparar a regra antiga com o mínimo estipulado pela EC95, percebe-se que o piso previsto por ela é um piso deslizante. Isto é, ao longo do tempo, o valor mínimo destinado à educaçáo cai em proporçáo das receitas e do PIB. Na simulação apresentada no Gráfico 1, que atualiza e adapta os cálculos de Rossi e Dweck (2016), o mínimo para educaçáo passa de 18 para $15,7 \%$ da RLI em 2026 e 12,6\% em 2036 ${ }^{12}$ (Gráfico 2).

Apesar do piso deslizante, existe a possibilidade teórica de aumentos nos gastos com educação acima do mínimo, pela redução de outros gastos. No entanto, ao estabelecer um teto que reduz o gasto público em proporção ao PIB, haverá uma compressão do conjunto de gastos sociais. De acordo com a simulação de Rossi e Dweck (2016, p. 4):

Os outros gastos federais (excluindo previdência e juros) que eram 7\% do PIB em 2015 serão de 0,6\% do PIB em 2036, o que não parece tecnicamente, tampouco politicamente, factível. Considerando uma improvável estabilização do gasto com a previdência em $8,5 \%$ do PIB, com um exercício aritmético simples e um crescimento econômico médio de 2,5\% mostra-se que é impossível — matematicamente impossível — o Brasil chegar em 2036 com um maior nível de gasto com saúde e educação em proporçáo ao PIB [...]. Isso porque, de acordo com a 
simulação, em 2036 o gasto primário do governo total será de $12,3 \%$ do PIB; se os gastos como previdência somarem $8,5 \%$ do PIB, sobram apenas 3,8\% do PIB, número inferior aos atuais gastos com educação e saúde, em torno de 4\% do PIB em 2016.

Um agravante, para o caso da educação, está no fato dos gastos com Manutenção e Desenvolvimento do Ensino (MDE) estarem bastante acima do mínimo constitucional. Os dados orçamentários de 2018, apresentados na Tabela 1 , mostram que o novo mínimo constitucional com MDE foi de R \$ 50,4 bilhóes enquanto que as despesas executadas foram de $\mathrm{R} \$ 64,4$ bilhóes. Há, portanto,

\section{Gráfico 2}

Mínimos para gastos federais com manutenção e desenvolvimento do ensino na regra antiga e na Emenda Constitucional no 95 (EC95).

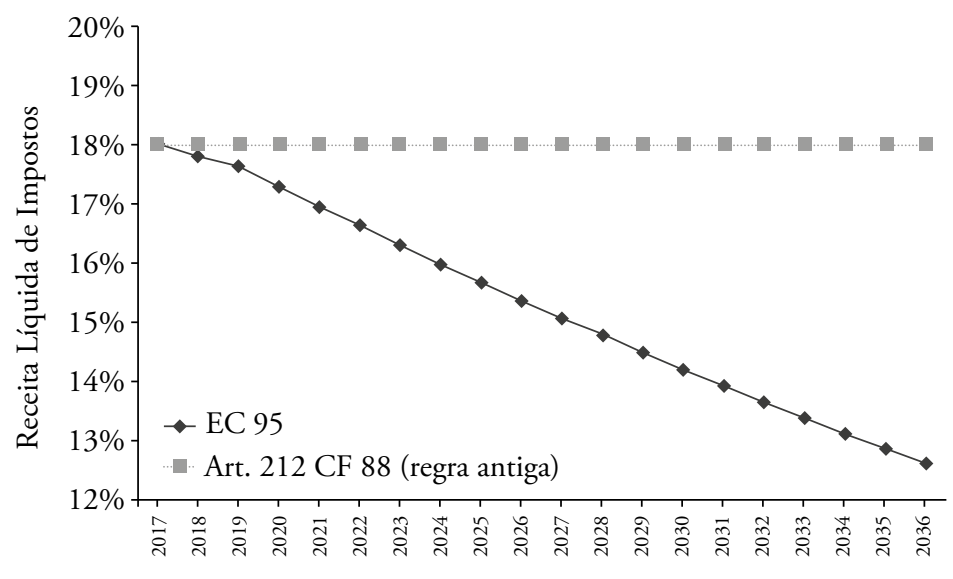

CF 88: Constituição Federal de 1988.

\section{Tabela 1}

Mínimos e execução de gastos da União com manutenção e desenvolvimento do ensino em 2018 (em milhares de R\$).

\begin{tabular}{lc}
\hline $18 \%$ da receita líquida de impostos do ano corrente (regra antiga) & 53.852 .633 \\
\hline $\begin{array}{l}18 \% \text { da receita líquida de impostos até dezembro/2017 corrigido pelo IPCA } \\
\text { de jul. } 2016 \text { a jul. } 2017 \text { (conforme a Emenda Constitucional no 95/2016) } \\
\text { (regra nova) }\end{array}$ & 50.450 .394 \\
\hline Despesas executadas de janeiro a dezembro de 2018 & 64.429 .497 \\
\hline Execuçáo em relaçáo ao limite minimo (no fim do ano, deve ser maior que 100\%) & $127,71 \%$ \\
\hline
\end{tabular}

IPCA: Índice Nacional de Preços ao Consumidor Amplo.

Fonte: com base em dados do Relatório Resumido da Execuçáo

Orçamentária da União (RREO em Foco - dez. 2018). 
despesas no valor de $\mathrm{R} \$ 14$ bilhóes que estarão sujeitas ao efeito achatamento e podem ser cortadas. Ademais, como esperado, observa-se que o novo piso constitucional já é inferior ao piso antigo, ou $18 \%$ da RLI, em R \$ 3,4 bi.

Esse cenário é desafiador para o futuro da educação pública no Brasil e mostra-se contraditório como as metas estabelecidas pelo Plano Nacional de Educação (PNE), aprovado 2014, com claro caráter expansionista dos direitos educacionais para garantir o acesso desde a creche até a pós-graduação (ARAÚJO, 2017).

Há um retrocesso flagrante na trajetória percorrida pelo país na busca por materializar o direito fundamental à educação, desde a CF/88 e a Lei de Diretrizes e Bases da Educação, passando pela aprovação do Fundeb em 2007, pela Lei do Piso em 2008 e pela EC59, em 2009, demonstrando o arcabouço legal de conquistas no período recente que culmina com a aprovaçáo do Plano Nacional de Educação (CARA; PELLANDA, 2018). Ao impedir a ampliação da oferta educacional, a austeridade representada pela EC 95 impede o cumprimento das metas e estratégias previstas no PNE.

O impeditivo no financiamento da educação pública favorece o processo de privatização em suas diversas formas (da oferta educacional, do currículo e da gestão da educação), a fim de buscar formas mais baratas de oferecer os serviços educacionais. Tais formas de prover o serviço podem vir a ser não mais uma exceção, mas a alternativa amplamente majoritária. Esse processo pode contar com a influência de instituiçóes filantrópicas e fundaçóes que, conforme aponta Adrião (2017), têm atuado na elaboração de políticas públicas e na formação de gestores educacionais no Brasil.

\section{Austeridade e o financiamento da educação nos últimos anos}

Para além do projeto de austeridade fiscal a longo prazo, cujo pilar é a EC95, os efeitos dos cortes de gastos já se fazem sentir desde 2015 com a virada na política macroeconômica. Quando se analisa a execução orçamentária da Função Educação (Gráfico 3), que considera todos os recursos federais destinados a pagamento de pessoal e encargos, despesas de custeio e investimentos relacionados aos programas da educação ${ }^{13}$, percebe-se que o governo federal interrompe a trajetória de aumentos das dotaçôes orçamentárias autorizadas para esses gastos em termos reais. $\mathrm{O}$ corte dos gastos públicos destinados à educação já ficou evidente a partir de $2015^{14}$, pois, após o máximo de $\mathrm{R} \$ 133,1$ bilhôes naquele ano, o orçamento autorizado para a função educação caiu para R \$ 119,1 bilhôes em 2016 e $\mathrm{R} \$ 116,0$ bilhóes em 2018. O Gráfico 3 ainda mostra que os empenhos ${ }^{15}$ caíram em termos reais de R \$119,6 bilhóes em 2015 para R \$ 113,9 bilhôes em 2018 e os gastos liquidados ${ }^{16}$ permaneceram no mesmo patamar (na média de $\mathrm{R} \$ 104,0 \mathrm{bi}$ ) nos últimos três anos. 
Entre os gastos mais impactados pelos cortes estáo os com investimento em educaçáo. O Gráfico 4 mostra que, enquanto os gastos liquidados com pessoal

\section{Gráfico 3}

Total de Gastos do Orçamento da União: Função Educação (preços de março 2019).

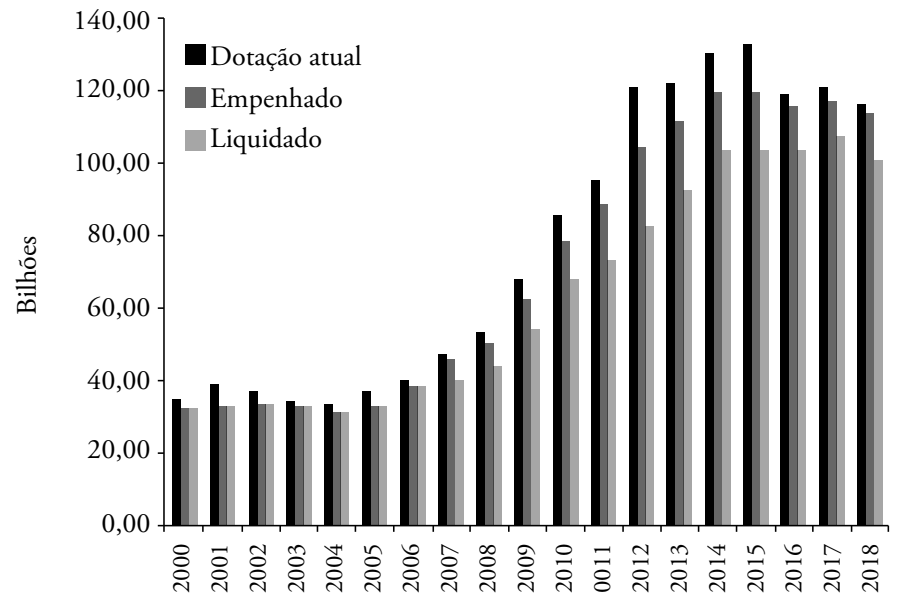

Fonte: dados do Sistema Integrado de Planejamento e Orçamento (SIOP).

\section{Gráfico 4}

Gastos reais liquidados do orçamento da Uniáo com educação*.

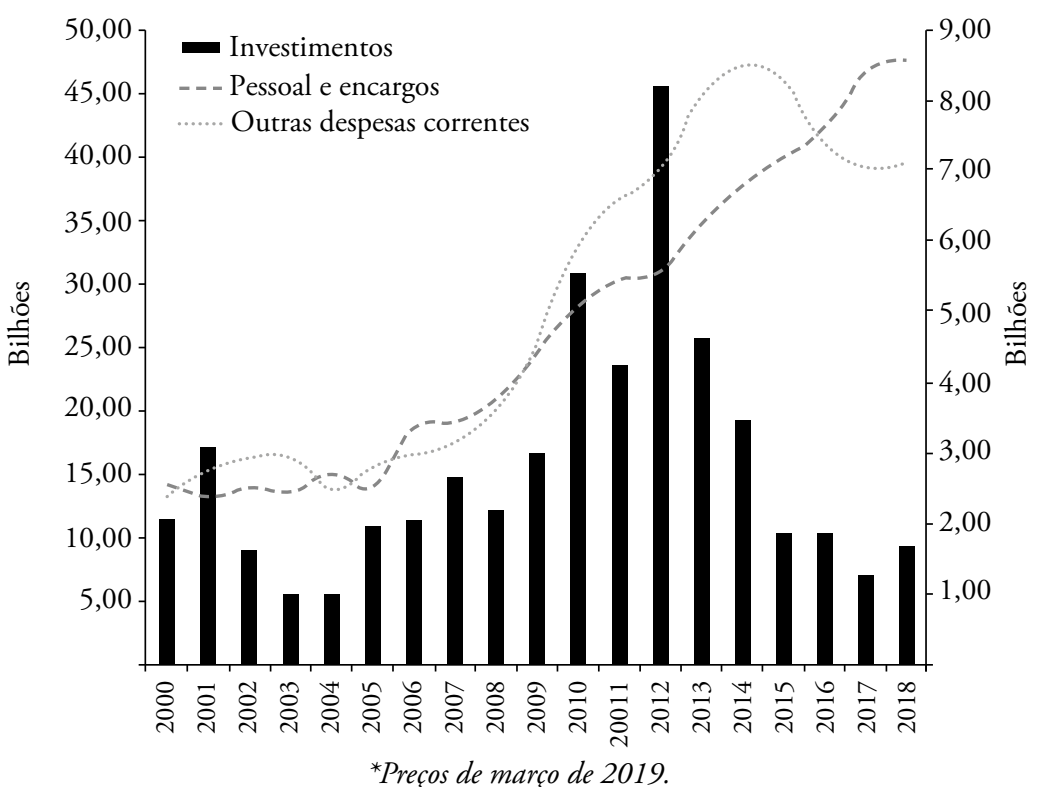

Fonte: Fonte: dados do Sistema Integrado de Planejamento e Orçamento (SIOP) 
e encargos cresceram ao longo da série, os gastos com investimento caíram a partir de 2012 e os gastos com custeio (outras despesas correntes) começaram a cair a partir de 2014. Os investimentos em educação retrocederam ao patamar de 2002, em torno de R \$ 1,7 bilhão, após o máximo de R \$ 8,2 bilhóes em 2012 e os gastos com custeio tiveram queda significativa nos últimos três anos, chegando ao patamar de R \$39,5 bilhóes em 2018.

Esses cortes implicam descontinuidade no crescimento do orçamento e de diversas políticas públicas. No ensino superior, por exemplo, houve queda do orçamento do Programa de Apoio a Planos de Reestruturação e Expansão das Universidades Federais (Reuni) a partir de 2015, com estagnação da quantidade de IFES e das matrículas nessas instituiçóes em 2014, ao contrário do que vinha ocorrendo desde o início do século (OLIVEIRA, 2019). De acordo com Oliveira (2019), também houve queda no número de novos contratos do FIES, que passaram de 733 mil em 2014 para 201 mil em 2016 e queda no número de bolsas (Capes e CNPq) em 2015.

\section{Considerações finais}

O tema da austeridade fiscal voltou recentemente ao centro do debate sobre as políticas públicas no Brasil e promete continuar a pautá-lo nos próximos anos. O discurso da austeridade ampara-se em uma lógica específica, extremamente questionada na literatura econômica. Conforme defendido neste artigo, a austeridade é uma ideia equivocada, do ponto de vista social, e contraproducente, do ponto de vista do crescimento econômico e do equilíbrio fiscal. Essa ideia atende a interesses específicos que se beneficiam dos cortes de gastos e da redução das obrigações sociais do governo.

Vimos também que o Brasil adotou a agenda da austeridade como um projeto a longo prazo por meio da EC95 que visa à redução do tamanho do Estado, medido pela relação gasto/PIB, nas próximas duas décadas. Conforme os cálculos apresentados, até 2026 o tamanho do gasto público no Brasil deve reduzir em torno de 6 pontos percentuais do PIB e voltar aos patamares de 1997. Assim, o teto de gastos provocará um efeito achatamento do conjunto dos gastos sociais, e o financiamento da educação estará suscetível aos cortes e desprotegido pela modificação do mínimo constitucional para a área.

Os efeitos dos cortes de gastos na área de educação já podem ser observados desde 2015, com queda na dotação de recursos para a área e, especialmente, para os gastos federais com investimento em educação dos gastos públicos que retrocederam ao patamar de $2002 \mathrm{em}$ termos reais.

A continuidade dessas políticas de austeridade pode comprometer o financiamento da educaçáo pública assim como o futuro das próximas gerações. Nesse contexto, faz-se necessário o acompanhamento sistemático dos impactos 
desses cortes de gastos, por meio de estudos acadêmicos, assim como um amplo debate público sobre a austeridade fiscal, seus impactos distributivos, seus beneficiários e prejudicados, e a concepçáo de Estado que está por trás de tais políticas.

Por fim, é necessário discutir as alternativas às políticas de austeridade que passem pelo fortalecimento da educação pública como vetor de desenvolvimento.

\section{Notas}

1. Ver por exemplo, Blyth (2013) e Rossi, Dweck e Oliveira (2018).

2. Ver, por exemplo, Alesina e Tabellini (1990) e Alesina e Perotti (1995).

3. O que ficou conhecido como a tese da contração fiscal expansionista.

4. Por exemplo, o Presidente do Banco Central, Ilan Goldfajn, afirmou em entrevista que "a atual recessão foi provocada por anos de excessos” Informação disponível em: https://valor.globo. com/brasil/coluna/desta-vez-e-diferente.ghtml Acesso em: 09/10/2019

5. Esse reconhecimento avançou para além dos argumentos keynesianos, como em Wolf (2013) e Krugman (2015), para o campo da modelagem convencional, como em Farmer e Zabczyk (2018).

6. Além disso, os autores constataram que os ajustes baseados em corte de gastos tendem a piorar ainda mais significativamente a desigualdade, em relaçâo aos ajustes baseados em impostos.

7. Além disso, os autores constataram que os ajustes baseados em corte de gastos tendem a piorar ainda mais significativamente a desigualdade, em relação aos ajustes baseados em impostos.

8. O percentual mínimo anterior para a União, determinado pela Emenda Constitucional 14 de 1983, era de $13 \%$ da receita de impostos. Para análise da evolução dos mecanismos de financiamento da educação pública, ver Pinto e Adrião (2006).

9. As variaçôes na proporção gastos/PIB refletem também a variação do denominador, ou seja, do PIB. Isso explica, por exemplo, o aumento dessa proporção em 2015, quando ocorre redução do gasto real primário da União. No entanto, a variação do denominador não invalida a análise da tendência de crescimento do gasto.

10. A metodologia aqui adotada está em linha com Brasil (2016), mas o mesmo padrão da evoluçáo das despesas primárias do governo central também pode ser verificado por diferentes metodologias, como em Gobetti e Orair (2017), Pires e Borges (2016) e Almeida (2015). Para uma comparação entres essas diferentes metodologias, ver Magalhães e Costa (2018).

11. O estudo de Cordes et al. (2015) faz um mapeamento dos tipos de regras de gastos estabelecidas internacionalmente.

12. A simulação considera o crescimento do PIB de 2018 (1,1\%), projeta $1 \%$ de crescimento para 2019 e que o PIB cresce $2 \%$ em média a partir de então. Além disso, supóe-se que a receita líquida acompanha o crescimento do PIB. 
13. Na Função Educação estão tanto os gastos diretos do Governo Federal em educação quanto as transferências governamentais por repartição de receita. Nos anos recentes, os gastos da função educação estão concentrados no Ministério da Educação e no Tesouro Nacional, que é responsável pelas Operaçôes Oficiais de Crédito, mas, no início da série, o Ministério das Cidades e o Ministério do Planejamento também destinavam recursos a essa função.

14. Série consolidada e de acesso público no Painel do Orçamento Federal, na base de dados do Sistema Integrado de Planejamento e Orçamento (SIOP), disponível em: <http://www1.siop. planejamento.gov.br/acessopublico/>. Acesso em: 09 de outubro de 2019.

15. Grosso modo, o empenho de recursos corresponde àquela fase da execução orçamentária em que se destinam, de fato, recursos para as dotaçóes autorizadas na LOA. Em outros termos, trata-se do reconhecimento por parte do governo de que possui o dinheiro separado para ser gasto em determinada área.

16. Já a liquidaçấo é a fase da execução orçamentária em que o governo contrata determinado serviço, verifica que o este foi executado conforme o contratado e reconhece que deve recursos financeiros ao prestador de serviços. Em outros termos, quando o governo liquida uma obra, por exemplo, ele atesta que a obra foi feita e que só falta transferir o dinheiro dos cofres públicos para o prestador de serviços.

\section{Referências}

ADRIÃO, T. A privatização da educação básica no Brasil: consideraçóes sobre a incidência de corporaçóes na gestão da educação pública. In: ARAÚJO, L.; MARCELINO, J. (orgs.). Público x privado em tempos de Golpe. São Paulo: Fundação Lauro Campos, 2017.

ALESINA, A.; PEROTTI, R. Fiscal Expansions and Fiscal Adjustments in OECD Countries. NBER Working Paper, n. 5214, 1995. http://doi.org/10.3386/w5214

ALESINA, A.; TABELLINI, G. A positive theory of fiscal deficits and government debt. Review of Economic Studies, v. 57, n. 3, p. 403-414, 1990. http://doi. org/10.2307/2298021

ALMEIDA, M. Evolução dos gastos públicos de 1990-2020. In: O DESAFIO FISCAL BRASIL. São Paulo: Insper, 2015.

ANSTEAD, N. The idea of austerity in British politics: 2003-13. Political Studies, v. 66, n. 2, p. 287-305, 2017. https://doi.org/10.1177\%2F0032321717720376

AQUINO, Y. Temer diz que confiança permite retomada do crescimento da economia. Agência Brasil, 2018. Disponível em: <http://agenciabrasil.ebc.com.br/economia/ noticia/2018-04/temer-diz-que-confianca-permite-retomada-do-crescimento-daeconomia $>$. Acesso em: 9 out. 2019.

ARAÚJO, L. Apresentação. In: ARAÚJO, L.; MARCELINO, J. (orgs.). Público x privado em tempos de Golpe. São Paulo: Fundação Lauro Campos, 2017.

ATKINSON, A. Public Economics in an Age of Austerity. Londres: Routledge, 2014. 
BLANCHFLOWER, D. et al. Jeremy Corbyn's opposition to austerity is actually mainstream economics. The Guardian, 2015.

BLYTH, M. Austerity: The History of a Dangerous Idea. Oxford University Press, 2013. BOVA, E.; KINDA, T.; WOO, J. Austerity and inequality: the size and composition of fiscal adjustment matter. Vox, 2018.

BRASIL. Constituiçáo Federal da República Federativa do Brasil. 1988. Disponível em: <https://goo.gl/kB3NGH >. Acesso em: 22 nov. 2018.

BRASIL. Evoluçáo dos gastos públicos federais no Brasil: uma análise para o período 2006-15. Brasília: Secretaria de Política Economia, 2016.

BRASIL. Emenda Constitucional 95/2016. Altera o Ato das Disposiçôes Constitucionais Transitórias, para instituir o Novo Regime Fiscal. 2016. Disponível em: <https:/goo.gl/ krEA9g>. Acesso em: 9 jan. 2019.

CAMMAERTS, B. The Circulation of Anti-Austerity Protest. Londres: Palgrave MacMillan, 2018.

CARA, D.; PELLANDA, A. Avanços e retrocessos na Educação Básica: da Constituição de 1988 à Emenda Constitucional 95. In: ROSSI, P.; DWECK, E.; OLIVEIRA, A.L.M. (orgs.). Economia para poucos: impactos sociais da austeridade e alternativas para o Brasil. São Paulo: Autonomia Literária, 2018. 375 p.

COCHRANE, J. Fiscal Stimulus, Fiscal Inflation or Fiscal Fallacies? 2009. Disponível em: <http://faculty.chicagobooth.edu/john.cochrane/research/Papers/fiscal2.htm $>$. Acesso em: 09 de outubro de 2019.

COELHO, A. Capitalismo como religiáo: uma crítica a seus fundamentos míticoteológicos. Tese (Doutorado) - Universidade Metodista de São Paulo, São Paulo, 2014.

CORDES, T. et. al. Expenditure rules: effective tools for sound fiscal policy? Washington, D.C.: International Monetary Fund, 2015. (Working Paper, WP/15/29).

FARMER, R. E. A.; ZABCZYK, P. The household fallacy. National Institute of Economic and Social Research, 2018. Disponível em: https://www.niesr.ac.uk/sites/default/files/ publications/DP487 0.pdf Acesso em: 10 out. 2019.

GOBETTI, S.W.; ORAIR, R.O. O resultado primário e contabilidade criativa: reconstruindo as estatísticas fiscais "acima da linha" do governo geral. Brasília: Ipea, 2017. (Texto para Discussão, n. 2288).

KELLY, P.; PIKE, J. Neoliberalism and Austerity: The Moral Economies of Young People's Health and Well-being. Bundoora: Palgrave MacMillan, 2017.

KEYNES, J. How to Avoid a Slump. In: MOGGRIDGE, D. World crises and policies in Britain and America. Londres: MacMillan/Cambridge University Press, 1937. v. 21. p. 384.

KRUGMAN, P. The Austerity Delusion. The Guardian, 29 abr. 2015. Disponível em: <https://www.theguardian.com/politics/2015/aug/23/jeremy-corbyns-opposition-toausterity-is-actually-mainstream-economics>. Acesso em: 09 de outubro de 2019. 
MAGALHÃES, L.C.G.; COSTA, C.R. Arranjos institucionais, custo da dívida pública e equilíbrio fiscal: a despesa "ausente" e os limites do ajuste estrutural. Brasília: Ipea, 2018. (Texto para Discussão, n. 2403).

MARTELLO, A.; MATOSO, F.; CALGARO, F. Novo ministro da Fazenda fala em corte de despesas, mas sem pacotes. G1, 2014. Disponível e: <http://g1.globo.com/economia/ noticia/2014/11/novo-ministro-da-fazenda-fixa-meta-fiscal-de-12-do-pib-para-2015. html>. Acesso em: 09 de outubro de 2019.

MENDOZA, K.A. Austerity: The Demolition of the Welfare State and the Rise of the Zombie Economy. Oxford: New Internationalist Publication, 2015.

MILIOS, J. Austerity Isn't Irrational. Jacobin Magazine, 2015.

OLIVEIRA, A.L.M. Educaçáo Superior brasileira no início do século XXI: inclusáo interrompida? Tese (Doutorado em Desenvolvimento Econômico) - Instituto de Economia, Universidade Estadual de Campinas, Campinas, 2019.

PINTO, J.M.R.; ADRIÃO, T. Noçóes gerais sobre o financiamento da educação no Brasil. EccoS Revista Científica, v. 8, n. 1, p. 23-46, jan.-jun. 2006.

PIRES, M.; BORGES, B. A despesa primária do Governo Central: estimativas e determinantes no período 1986-2016. Rio de Janeiro: FGV-IBRE, 2016.

RAO, P.K. Government Austerity and Socioeconomic Sustainability. Princeton: Springer, 2015.

REDAÇÃO. Meirelles: desafio número um é recuperar a confiança. Veja, 2016. Disponível em: <https://veja.abril.com.br/economia/meirelles-desafio-numero-um-e-recuperar-aconfianca/>. Acesso em: 9 out. 2019.

ROSSI, P.; DWECK, D. Impactos do novo regime fiscal na saúde e educação. Cadernos de Saúde Pública, v. 32, n. 12, p. 1, 2016. http://dx.doi.org/10.1590/0102-311x00194316 ROSSI, P.; DWECK, E.; OLIVEIRA, A.L. (orgs.). Economia para poucos: impactos sociais da austeridade e alternativas para o Brasil. São Paulo: Autonomia Literária, 2018. 375 p.

SCHUI, F. Austerity: The Great Failure. Londres: Yale University Press, 2014.

SISTEMA INTEGRADO DE PLANEJAMENTO E ORÇAMENTO (SIOP). Disponível em: <http://www1.siop.planejamento.gov.br/acessopublico/>. Acesso em: 10 out. 2019.

SKIDELSKY, S.; FRACCAROLI, N. (orgs.). Austerity vs. Stimulus: The Political Future of Economic. Londres: Palgrave MacMillan, 2017.

STUCKLER, D.; BASU, S. Economia desumana: porque mata a austeridade. Lisboa: Bizancio, 2014.

TESOURO NACIONAL. Administração Orçamentária e Financeira. 2019. Disponível em: https://www.tesouro.fazenda.gov.br/-/area-tematica-1-administracao-orcamentaria-efinanceira Acesso em: out. 2019. 
TESOURO NACIONAL. Relatório Resumido da Execução Orçamentária da União. RREO em Foco, 2018. Disponível em: <http://www.tesourotransparente.gov.br/temas/contabilidadee-custos/relatorio-resumido-da-execucao-orcamentaria-rreo $>$. Acesso em: 10 out. 2019.

WEBSTER, M. Word of the Year Retrospective. 2014. Disponível em: <https:// www.merriam-webster.com/words-at-play/2014-word-of-the-year-retrospective $>$. Acesso em: 9 out. 2019.

WOLF, M. How Austerity has Failed. Nova York: The New York Review of Books, 2013. ZWEINIGER-BARGIELOWSKA, I. Rationing, Controls, and Consumption, 19391955. Oxford: Oxford University Press, 2000.

\section{SOBRE OS AUTORES}

Pedro Rossi é professor do Instituto de Economia da Unicamp, pesquisador do Centro de Estudos de Conjuntura e Política Econômica (CECON) da Unicamp e coordenador do Conselho Editorial do Brasil Debate.

Ana Luíza Matos de Oliveira é economista pela UFMG, mestra e doutora em Desenvolvimento Econômico pela Unicamp e Professora Visitante da FLACSO - Brasil.

Flávio Arantes é economista, mestre e doutorando em Economia pela Unicamp, pesquisador do CECON da Unicamp. Atuou como Técnico em Planejamento e Gestão da Fundação do Desenvolvimento Administrativo de São Paulo (FUNDAP).

EsTHer Dweck é professora associada do Instituto de Economia da UFRJ. Tem experiência na área de Macroeconomia, com ênfase em Integração Micro-Macro, Economia do Setor Público, Crescimento e Desenvolvimento Econômico.

Recebido em 2 de maio de 2019.

Aceito em 6 de setembro de 2019. 